\title{
Direitos humanos e
}

ética da libertação: Pretensão política de justiça e a luta pelo reconhecimento dos novos direitos ${ }^{1}$

Human rights and ethics of liberation: justice policy claim and the struggle for recognition of new rights

Enrique Dussel ${ }^{2}$

Resumo: O presente ensaio, inserido em um horizonte de construção de uma ética da libertação e de uma filosofia política crítica, pretende analisar a historicidade dos direitos humanos e sua importância na seara das instituições políticas vigentes. A partir de uma pretensão política de justiça, toma-se em conta o sistema do direito em sua contínua tensão entre o vigente e não vigente, abrindo espaço para que os novos movimentos sociais, em suas reivindicações, conquistem novos direitos, superando sua exclusão no âmbito formal. Assim, configura-se uma luta por reconhecimento dos sem-direitos a partir da sociedade civil, modificando as estruturas estatais.

Palavras-chave: Direitos humanos; ética da libertação; justiça; novos direitos; novos movimentos soicias.

1 Este artigo tem sua origem na palestra apresentada no VII Seminário do Programa de Diálogo Norte-sul, em El Salvador, em julho de 1998, com a presença esperada de K. O. Apel, F. Hinkelammert e de muitos outros colegas. [Tradução de Ricardo Nery Falbo a partir da versão publicada em DUSSEL, Enrique Domingo. Hacia una filosofía política crítica. 2 ed. Bilbao: Desclée de Brouwer, 2011, p. 145-157.]

2 Filósofo argentino-mexicano, professor da Universidade Nacional Autônoma do México (UNAM) e da Universidade Autônoma da Cidade do México (UACM). 
Abstract: This issue, inserted in a horizon of building an ethic of liberation and a critical political philosophy, aims to analyze the historicity of human rights and their importance in the sphere of political institutions $i$ force. From a justice policy claim, it takes into account the system of rights in its continuing tension between legal and non-legal force, making room for new social movements, in their demands, conquer new rights, surpassing its exclusion from the formal framework. So there is a struggle for recognition of rights from civil society, modifying the state structures.

Keywords: Human rights; ethic of liberation; justice; new rights; new social movements.

\section{PRETENSÃO POLÍTICA DE JUSTILCA}

Pode parecer que a ética filosófica trata de atos "bons" ou "maus". Não obstante isto, como pretenderemos demonstrar, não é este exatamente o propósito da ética, porque seria um objeto impossível de reflexão. De fato, a ética se ocupa das condições universais da norma, do ato, da micro - ou macro - estrutura social, da instituição ou do sistema de eticidade como totalidade ${ }^{3}$, considerados sob a perspectiva de sua "bondade" (ou "maldade"), num sentido por ora amplo. Porém, como a condição de possibilidade de ditos atos são as decisões ou as conseqüências a curto ou longo prazo, ninguém pode, em concreto, decidir com base numa "deliberação perfeita" nem tampouco pode pretender possuir uma predicção certa, também perfeita, acerca das ditas conseqüências (especialmente se se tem em conta as conseqüências a longo prazo como efeito negativo não-intencional). Uma decisão prática perfeita ou uma predicção perfeita, absolutas, são praticamente impossíveis para a condição humana finita - teria de pretender possuir uma inteligência infinita com velocidade infinita, tal como exige Popper, ao argumentar contra a planificação perfeita do historicismo extremo e utópico. Há, então, decisões e predicções de efeitos aproximados, falseáveis, provisórios. Porém, neste caso, não

3 Ver minha Ética da Liberação na idade da globalização e da exclusão, Dussel, 1998. 
poderíamos dizer de maneira apodítica: “- Este ato é bom!”. A ética, parece, fica sem propósito. Todavia, não é assim.

Do fato de que os atos incluem um momento de indecisibilidade por falta de evidência prática absoluta e de impredictibilidade perfeita, isto é, de que seja impossível ter uma certeza absoluta de seus efeitos, não decorre que a ética perca seu sentido. $O$ que acontece é que o propósito da ética é outro.

Em primeiro lugar, a ética - como eu a entendo - estuda as condições universais da constituição do ato (norma, instituição, etc.) como "bom" (ou "mau"), e estas condições valem para todo ato concreto, contingente. A universalidade do nível dos princípios ${ }^{4}$ não nega, e sim fundamenta, a possibilidade de um ato concreto e contingente com a honesta "pretensão ${ }^{5}$ de bondade". As condições universais (o momento material de verdade prática como mediação da reprodução da vida humana, o momento formal de validez consensual como exigência de participação simétrica do interessado, o momento de factibilidade da razão instrumental, que delimita o "possível" empírica e historicamente) são condições da "pretensão de bondade". Um ato tem "pretensão

4 Que eu denomino "nível A" (analogicamente à Teil A de Apel).

5 A palavra "pretensão" (em alemão Anspruch, em inglês claim) abre um âmbito próprio entre a) o "necessário" (que não pode ser de outra maneira e, contudo, não é falseável, corrigível) e c) o puramente "contingente" (que é singular, único, irrepetível). É o âmbito b) entre b.1) um a priori no qual se tem honestamente procurado atender a todos os requesitos possíveis (possíveis para a finita condição humana, que não tem onisciência), e b.2)um a posteriori que manifesta um efeito contingente negativo não-intencional. A "não-intencionalidade" (em inglês unintentional, já proposta por Adam Smith para conotar os atos realizados no mercado) é constitutiva da "pretensão", porque, ao ter consciência (da decisão inadequada ou da consciência negativa), o ato perde sua honesta (seria desonesta, hipócrita, encobridora) "pretensão de bondade". Além disto, a "pretensão de bondade" (como aquela com a qual propomos a continuação: "pretensão política de justiça") não pode ser confundida com a expressão apeliana-habermasiana "pretensão de validez" (Gültigkeitsanspruch), que só se situa no nível formal do consenso da razão discursiva. A "pretensão de bondade" que propomos (fruto de toda nossa obra Ética da Libertação, 1998) conta não somente com o consenso discursivo (momento formal), mas igualmente com a realização do momento material (a produção e reprodução da vida humana em comunidade), da factibilidade prática e empírica e do levar em conta os efeitos negativos não intencionais do ato (as vítimas) e tudo o que isto supõe praticamente (até serem responsáveis por sua libertação). A "pretensão de validez", com a "pretensão de verdade" (material), a "pretensão de eficácia" (factibilidade) e a "pretensão ético-crítica" (do ter levado em conta as vítimas), constitui a complexa, e até o presente não estudada, "pretensão de bondade". 
de bondade ${ }^{6 "}$ quando honestamente satisfaz estes três componentes (material, formal e de factibilidade). Mas, isto não é suficiente.

Um ato com "pretensão de bondade" deve (e esta exigência deontológica é um dever em sentido estrito) assumir suas conseqüências (num sentido muito mais estrito e profundo que a mera "ética da responsabilidade" de Max Weber, e assim como a de Hans Jonas), em especial eticamente, quando são efeitos negativos não-intencionais, porém não menos objetivos, observáveis, descobríveis - como os dos Relatórios do PNUD das Nações Unidas, sob a orientação científica de um Amartya Sen, Prêmio Nobel de economia $1998^{7}$ - que os fatos empíricos das ciências "duras". Para que o agente permaneça com "pretensão de bondade" deve corrigir seu ato (sua decisão, seus efeitos). O falseamento ou correção do ato não mostra que ele era "mau" e que teria agora de ser convertido em "bom".

O ato não podia ser "mau" porque foi séria e honestamente produzido, tendo clara "pretensão de bondade" ou tendo, dentro da condição humana finita, cumprido seriamente as condições universais. $\mathrm{O}$ ato deve ser corrigido não porque foi "mau" (porque neste não poderá nunca tampouco ser "bom", porque na realidade terá sempre de efetuar uma correção contínua, perfectiva, porém não perfeita), mas porque toda "pretensão de bondade" pressupõe a finitude do ato e inevitavelmente os aspectos negativos (porque a decisão da máxima não é perfeita, nem perfeita é a predicção de suas conseqüências). É inevitável que "o justo cometa sete pecados por dia", diz um provérbio antigo. Não é por não cometer pecado que ele deixa de ser "justo"; deixaria de ser "justo" se não corrigisse os efeitos advindos de seus pecados. 0 agente com "pretensão de bondade" não pode deixar de cometer atos injustos, porém deve honestamente corrigi-los para seguir sendo "justo", isto é, um agente com permanente "pretensão de bondade". Desta maneira, a universalidade dos princípios não nega a contingência dos

6 Questões formuladas na primeira parte de minha Ética da Libertação (1998).

7 Cf. o capítulo VI "Princípios éticos e economia", de meu livro Hacia una filosofía política crítica. 2 ed. Bilbao: Desclée de Brouwer, 2011, p. 127-144. 
atos ${ }^{8}$ nem a necessidade das condições universais, a falibilidade, exigência de falseamento e correção dos atos éticos.

De sua parte, o ato político (igualmente a norma política, a micro-e macro- estrutura, a instituição e o sistema completo político) tem determinações específicas, próprias da esfera pública na qual se move, $e$, como agência que enfim participa de uma comunidade política com soberania popular, o político (que se subsume ao ético como suas condições de possibilidade e constituinte originário enquanto político) tem, como o ético, diversos níveis de generalidade.

O nível $A^{9}$ é o das condições dos princípios universais da Política enquanto tal. A Política se ocupa: a) das condições ou princípios da produção e reprodução da vida da comunidade política (num nível ecológico-econômico, em sentido amplo, como nível dos conteúdos da razão política prático-material); b) das condições ou princípios dos procedimentos normativos de legitimidade consensual (no nível do Princípio Democrático em todos seus aspectos, como regulação da participação pública e simétrica dos interessados, âmbito da razão discursivo-política); c) das condições ou princípios da factibilidade política na realização dos meios e fins da ação concreta (princípios que regem a luta pela hegemonia e no exercício do poder político, nível da razão estratégico-instrumental propriamente dita).

O nível B é o das mediações sistêmicas. Aí se realizam institucionalmente as condições universais por meio de sistema concretos. Em primeiro lugar, a) os sistemas materiais ecológico-econômicos; em segundo lugar, b) os sistemas formais procedimentais do exercício legítimo do poder político (onde, como veremos, entra todo o sistema do direito); e, por último, c) o sistema do Estado, como macro-instituição do exercício monopolístico do poder político em última instância, ao serviço dos aspectos já indicados (a e b).

8 Num nível C (seria uma inexistente Teil C em Apel). É justamente o nível da luta pela hegemonia honesta, contingente (como quer R Rorty e E. Laclau), mas com princípios universais (não fundacionalistas nem dogmáticos). Tudo isto desenvolveremos mais extensamente em Uma Política de Libertação, dentro do discurso da Ética da Libertação, em elaboração. Veja o capítulo X "Povo e hegemonia. Uma conversação com Ernesto Laclau”, neste livro. 
Há, todavia, um nível $\mathrm{C}$, o da ação política concreta; é onde se expõe toda uma teoria da dita ação, da lógica da luta política pela hegemonia, da maneira do exercício do poder e do uso monopolístico da coação para fazer respeitar o "estado de direito", tendo em vista o bem comum. É aqui onde a "pretensão de bondade" ética é subsumida ${ }^{10}$ na "pretensão política de justiça". Denominarei "pretensão política de justiça" a determinação da norma, do ato, da micro - ou macro- estrutura, da instituição ou sistema políticos que tenham realizado de maneira honesta e séria as condições (ou princípios universais) antes enunciados. Aqui não posso estender-me sobre todas estas distinções, e, por isto, a análise que se ocupou de todas estas questões será objeto de uma obra em desenvolvimento (Uma Política de Libertação). De toda forma, a título de resumo, o ato político normativamente adequado é a "Política" com maiúscula, a do estadista que luta a longo prazo pela sobrevivência da humanidade e pela simetria democrática dos interessados (em especial das vítimas), e não a "política" com minúscula, a de $\mathrm{M}$. Weber, do mero profissional para quem suas vítimas lhe são invisíveis, profissional do lucro, da fama ou do mero propósito estratégico schmittiano de vencer o "inimigo".

Todo ato político obtém sua normatividade desta "pretensão política de justiça". Ato político que deverá ser corrigido (a falibilidade da finitude da condição humano-política) em tudo aquilo em que mostre que as condições necessárias da dita "pretensão" não foram realizadas hic et nunc. Por isto, a ação política com "pretensão política de justiça" pode e deve ter toda a possível "sabedoria" política estratégica e instrumental necessária no horizonte do "possível" normativamente na luta pela hegemonia contra os antagonistas, como expõe E. Laclau, já que razão e eficácia política não estão unidas a longo prazo com a luta pela vida da comunidade (basicamente de toda a humanidade) nem com a luta para alcançar a simétrica participação democrática dos interessados (os dois momentos normativos fundamentais).

10 Uso o conceito "subsunção" da maneira como Marx indicava que o "trabalho vivo" é subsumido no capital como uma determinação interna. Neste caso, alienante, mas não é assim a ética na política. Na política ocorre uma subsunção includente não alienante. 


\section{O "SISTEMA DO DIREITO" E SUA INOVAÇÃO NA HISTÓRIA}

Como temos indicado, no nível B ou das mediações sistêmicas da política, junto aos sistemas ecológico-econômicos (materiais, e estes que possibilitam a factibilidade do político enquanto tal (o sistema do Estado, no final das contas), e em referência ao âmbito que guarda certa autonomia (como é a esfera da opinião pública no âmbito da Sociedade Civil, que não deve ser confundida com o Estado, sociedade política para A. Gramsci), existe no sistema político como totalidade um aspecto formal, que garante a legitimidade procedimental, por meio da participação simétrica dos interessados e que pública e politicamente temos denominado "Princípio Democrático". Este princípio determina por dentro a primeira institucionalidade da comunidade política originária, que, como soberania popular, é a que "se dá as normas" públicas e por isto se obriga a obedecê-las. A soberania política, então, deve ser entendida no sentido de que a mesma comunidade (e cada membro) se autoconstitui com o dever de cumprir a lei que ela autopromulgou democraticamente.

Assim surge um "sistema do direito", que desempenha dentro do sistema político uma função específica que queremos determinar de maneira muito generalizada. A "pretensão política de justiça" tem no sistema de direito sua garantia procedimental formal de legitimidade. É uma "legítima pretensão" porque respeita a um marco de decisões institucionais que autorregulam sua ação pública, enquanto, em comum acordo (simétrico-democrático) com todos os demais afetados, produziu regras, normas, uma Constituição, leis que valem ${ }^{11}$ para todos os cidadãos equitativamente.

Isto é, o "sistema do direito" desempenha dentro do sistema político uma função específica, a de constituir a referência formal ou a institucionalização dos deveres e direitos que devem cumprir todos os membros da comunidade política enquanto soberana. Trata-se da constituição de um "estado de direito" (Rechtsstaat). Como um corpo

11 Evidentemente, este é um problema de "validez" (Gültigkeit) formal, e não de "verdade" (Warheit) material (vejam estas questões em minha Ética da Libertação, 1998, caps. 1-3). 
diferenciado onde os direitos fundamentais institucionalizados permitem promulgar uma "Constituição (em cumprimento do Princípio Democrático) como referência próxima do direito positivo em todos seus ramos. Estes ramos vão sendo promulgados até completar todos os órgãos requeridos para o exercício do indicado "estado de direito".

O "sistema do direito vigente" rege as condutas dos cidadãos partícipes de uma comunidade política que chegou a institucionalizar historicamente o marco legítimo que permite que as ações sejam legais. É evidente que o "sistema do direito vigente" é fruto por institucionalização do exercício de um Poder comunicativo (diria Hannah Arendt) que teve de contar com a hegemonia sobre a Sociedade Política (e de alguma maneira também sobre a Sociedade Civil). O "estado de direito" é assim o momento em que os participantes com hegemonia in actu podem atuar legalmente e realizar seus fins (diria M. Weber com base na sua definição do "poder" como "dominação"). Este sistema tem, por definição, o monopólio do uso da coação legítima.

\section{OS SEM-DIREITOS}

A situação crítica que interessa à Ética (e esta, à Política) da Libertação se apresenta quando certos cidadãos são excluídos não-intencialmente do exercício de novos direitos que o "Sistema do direito" não pode, todavia, incluir. Estes cidadãos com consciência de serem sujeitos de novos direitos se experimentam a si mesmos como vítimas $^{12}$, sofrendo inevitavelmente os efeitos negativos do corpo do direito ou de ações políticas, no melhor dos casos não-intencionais. São as gerações futuras diante dos crimes antiecológicos das gerações presentes; é o caso da mulher na sociedade machista, das raças não brancas na sociedade racista ocidental, dos homossexuais nas estruturas heterossexuais, dos marginais, das classes exploradas por uma economia do lucro, dos países pobres e periféricos, dos imigrantes e ainda dos Estados nacionais debilitados pela estratégia do capital global nas mãos de corporações transnacionais (às quais não se pode,

12 Veja o cap. 4 de minha referida Ética da Liberação (1998). 
no momento, impor um marco legal internacional que exija um serviço para a humanidade, e no estado atual de autorreferencialidade total e de destruição ecológica ou social, como efeito de suas estratégias como aumento de pobreza no mundo).

As vítimas de um "sistema do direito vigente" são os "sem-direito" (ou os que não têm, todavia, direitos institucionalizados, reconhecidos, vigentes). Trata-se, então, da dialética de uma comunidade política com "estado de direito" em face de muitos grupos emergentes sem-direitos, vítimas de sistemas econômico, cultural, militar, etc., vigentes.

Os "direitos humanos" não podem ser contabilizados a priori, como pretendia um possível direito natural. Por natureza, os direitos humanos são históricos. Isto é, eles se estruturam historicamente como "direitos vigentes" e são considerados com base na consciência ético-política dos "novos" movimentos sociais que lutam pelo reconhecimento de sua dignidade negada. Não pode haver a priori, no começo da história, uma "lista" dos direitos humanos. No final da história, quando tivesse lutado pelo reconhecimento de todos os direitos possíveis que o ser humano pudesse potencialmente descobrir em seu longo caminhar, poder-se-ia obter tal "lista", mas seria então a posteriori. Contudo, esta lista final careceria completamente de sentido ao final da história; o direito já não interessaria; seria como pretender direitos no momento da morte. No tempo do decurso da história, nunca se podem descobrir listas de todos os direitos humanos, salvo apenas daqueles que historicamente foram sendo descobertos, reconhecidos e institucionalizados como "direitos vigentes" (nos "sistemas do direito" históricos) e foram sucessivamente repensados com base nos "novos" direitos de cujos conteúdos tomam consciência, em primeiro lugar e sempre, os "sem-direito". Os movimentos dos "sem-direito-todavia" (com relação ao "direito vigente") começam uma luta pela inclusão dos "novos" direitos na "lista" histórica dos direitos já aceitos, institucionalizados, vigentes. A dialética não se estabelece então entre: "direito natural a priori versus direito positivo a posteriori”, sendo o direito natural a instância crítica a priori do direito positivo, reformável, cambiável, e sim entre: "direito vigente a priori versus novo direito a posteriori, sendo o 
novo direito a instância crítica a posteriori (isto é, histórica), e o direito vigente, o momento positivo, reformável, cambiável.

Neste caso, o "estado de direito" é uma condição histórica e o meio (umwelt) evolutivo na história, que se manifesta como a tradição crescente do mundo do direito de uma comunidade política que conta com a macro-institucionalidade do Estado. Os "sem-direito-todavia", quando lutam pelo reconhecimento de um novo direito, são o momento criador histórico, inovador, do corpo do direito humano. Não caímos assim no dogmatismo do direito natural (solução fundacionalista metafísica e inaceitável), nem tampouco no relativismo (todo direito vale por ter-se imposto pela força numa época), ou no mero contingencialismo (não há princípios universais), e sim na conciliação de um universalismo não-fundacionalista, que mostra que os "novos" direitos são aqueles exigidos universalmente (seja em uma cultura, seja para toda a humanidade, segundo o grau de consciência histórica correspondente) para a comunidade política no estado de sua evolução e crescimento histórico. Não era factível (pelas condições históricas concretas) o movimento feminista na Idade Média (embora tenha havido heróicas antecipações), como tampouco era possível o ecologismo antes da revolução industrial, quando o Planeta parecia, todavia, uma fonte inacabada de recursos, e os efeitos negativos sobre a reprodução da vida eram quase não mensuráveis.

\section{LUTA PELO RECONHECIMENTO DOS NOVOS DIREITOS DOS NOVOS MOVIMENTOS SOCIAIS DA SOCIEDADE CIVIL}

A incorporação de "novos" direitos ao "sistema do direito", ou a explosão do "sistema do direito" vigente, que agora se transforma em "antigo", por um novo sistema do direito, é fruto não tanto da explicitação de um direito natural, contudo não descoberto, e sim da institucionalização de um «novo» direito descoberto pelas vítimas «sem-direito», fruto da maturidade histórica própria ao desenvolvimento da realidade humana (e da consciência política), do processo civilizatório 
da comunidade política particular ou da humanidade em geral. Dito «descobrimento» não é fruto nem de um estudo teórico nem de um voluntarismo de certos movimentos messiânicos. É fruto da consciência crítico-política dos grupos que sofrem em sua dor os efeitos negativos do estado-de-não-direito de uma dimensão humana que a maturidade histórica desenvolveu, mas que o direito não incluiu, contudo, como exigências que requerem institucionalidade pública. A negatividade material (a miséria, a dor, a humilhação, a violência sofrida, etc.) indica para o «sem-direito» como um «vazio» negro dentro do «sistema do direito». É a dor, fruto da violência familiar e da humiIhação do patriarcalismo em face de seus próprios filhos, da própria corporalidade sofrente da mulher oprimida pela cultura machista (no nível sexual, social, econômico cultural, religioso, etc.), que permite subjetiva e publicamente «descobrir» sua inexistência no "sistema do direito vigente». A luta das sufragistas inglesas (que supunha a maturidade histórico política de dar o direito ao voto a cidadãos - inexistente nas monarquias medievais -, e depois de estender primeiro o voto aos varões não letrados e não proprietários) pelo "novo" direito à participação da mulher nas votações da democracia moderna é fruto, em primeiro lugar, da mulher mesma, da mulher sofrente (a "negatividade material" que nos recorda M. Horkheimer) que toma consciência de ser um "sujeito-sem-direito". A luta pelo reconhecimento do dito descoberto "em-negativo" é a origem histórica dos novos direitos do novo corpo de direito que se agregara à "lista" dos direitos humanos. É, evidentemente, um descobrimento histórico a posteriori; não é um direito natural a priori, nem é tampouco um direito positivo. É, simplesmente, a consciência de um "novo" direito descoberto na maturidade do processo histórico (este direito e não qualquer outro, longe de todo relativismo), mas não-institucionalizado, não-positivizado. A dialética, como temos indicado, não é a do "direito natural - direito positivo", e sim entre "direito vigente - novos direitos históricos".

Por outro lado, o "novo" direito pode encontrar-se: a) num estado de "constituição originária" na consciência política dos novos movimentos sociais como um "direito pelo qual se luta para que seja reconhecido" (isto é, um direito existente na consciência do novo ator histórico, mas 
não objetivamente existente como "sistema do direito vigente ${ }^{13}$ "); b) num estado "positivamente" institucionalizado como direito futuro vigente (que é o objetivo das lutas pelo reconhecimento dos direitos dos novos movimentos sociais).

É evidente que no "tempo intermédio", isto é, entre o tempo a) da auto-referência "fechada" sobre si mesma do "sistema do direito vigente" que nega (e lança toda a violência monopolística do Estado contra os novos atores sociais) ${ }^{14}$ o tempo e b) do "novo" direito institucionalizado, se produz, como já temos indicado, um triplo processo: 1) por um lado, de "deslegitimação" do direito vigente que começa a transformar-se em direito "antigo"; 2) por outro, de "legitimação" do novo direito que, a partir de uma posição de não-vigência e não-legítimo, passará lentamente a uma situação de legitimidade triunfante; 3) por último, produzir-se-á a derrogação de certos aspectos do direito antigo claramente contraditórios com o novo direito. O processo de deslegitimação é simultâneo e contrário ao da legitimação do novo direito. Isto é, o processo de legitimação originário parte inevitavelmente da ilegalidade ilegítima, assim como o processo de deslegitimação deverá ir reconhecendo, diante da luta pelo reconhecimento dos sem-direitos, a ilegalidade crescente de sua antiga legalidade.

13 Não é, então, um direito natural a priori, e sim que é historicamente descoberto e institucionalizado.

14 Trata-se agora de "violência" e não de mera "coação". O Estado tem o monopólio da coação legítima contra os cidadãos e para salvaguardar o "estado de direito" contra os membros do corpo político que, aceitando o sistema do direito, realizam atos contrários ao dito sistema (o ladrão, por exemplo). Porém, quando o feminismo se opõe ao patriarcalismo do sistema do direito já não é um simples ladrão, porque ele se opõe ao sistema do direito enquanto paternalismo. O sistema do direito paternalista deixou de ser legítimo para as feministas. Seu "crime" não é opor-se a uma lei que se afirma como legítima, e sim que é um oporse a uma lei que perdeu para elas legitimidade em sua totalidade. Neste caso, quando a coação se usa contra atores sociais que têm clara consciência de haver descoberto novos direitos, e por isto de encontrar-se num momento de legitimação do novo direito (e por isto de deslegitimação do sistema do direito vigente, então patriarcalista), a coação (exercício da força com base no direito legítimo) se transforma em violência (exercício da força contra o direito "nascente" do outro e por isto num processo de deslegitimação da ordem legal com base no qual se exercia a coação: agora por isto mesmo: violência). Tudo isto foi tratado no S 6.4 da Ética da Libertação (1998). 


\section{Esquema 5}

\section{Processos de deslegitimações e novas legitimações}

\begin{tabular}{|c|c|c|}
\hline $\begin{array}{c}\text { Sistema do direito vigente } \\
\text { (legitimação 1) }\end{array}$ & Processo de deslegitimação & $\begin{array}{c}\text { llegítimo 2 } \\
\text { (sistema do direito antigo) }\end{array}$ \\
\hline $\begin{array}{c}\text { Os sem-direitos } \\
\text { (ilegítimo 1) }\end{array}$ & Processo de legitimação & $\begin{array}{c}\text { Legítimo 2 } \\
\text { (Novo sistema do direito) }\end{array}$ \\
\hline
\end{tabular}

O novo direito vigente (legítimo 2) subsume todos os direitos anteriores (legítimo1) que não perderam vigência diante do processo de legitimação dos "sem-direitos", como movimentos de libertação. Mas, ao mesmo tempo, muitos momentos legítimos do antigo direito tornaram-se ilegítimos (ilegítimo 2). Desta maneira, é preservada a bipolaridade necessária para tornar possível o momento crítico do direito, mas sem referência a uma ordem natural a - histórica, e, não obstante isto, não se cai no relativismo historicista nem no universalismo abstrato. Há universalidade e contingência. A bipolaridade do direito vigente antigo e do novo direito vigente tem a vantagem sobre a bipolaridade antiga (direito natural - direito positivo), embora ambos sejam históricos, no que diz respeito, sem embargo, ao fato de o novo direito vigente ter sido o fruto de um processo crítico-criador dos movimentos que lutaram pelo reconhecimento destes novos direitos, antes não institucionalizados.

Desta maneira, a "pretensão política de justiça", que honesta e seriamente satisfazia no passado o direito vigente antigo, pode agora, com base nas vítimas (os sem-direitos que lutando institucionalizaram novos direitos), vítimas de ações injustas (justas, legais e legítimas com base no direito antigo; injustas, ilegais e ilegítimas com base no novo direito), corrigir os erros próprios da autorreferencialidade do direito antigo, correção que supõe ações diferentes com base no ponto de vista do novo direito. O honesto político de antes, com "pretensão política de justiça", prossegue tendo no presente, por correção, a mesma "pretensão".

No tempo, na tradição da história do direito, há ao menos três níveis: 


\section{Esquema 6}

\section{Derrogação, permanência e inovação no corpo do direito}

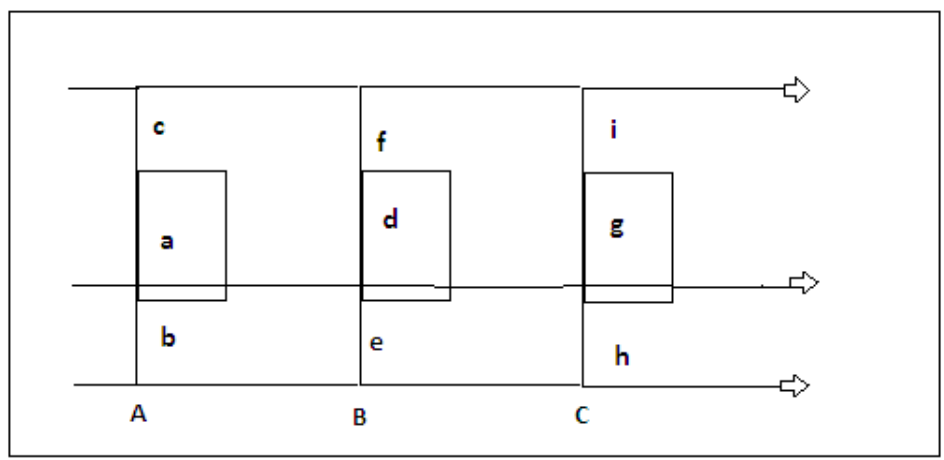

(Esclarecimento do esquema 6: A Direito antigo; a aspecto inovador do direito antigo;b aspecto do direito antigo que será derrogado; c aspecto do direito antigo que será subsumido no novo direito. E Novo direito; d aspecto inovador do novo direito; e aspecto que será derrogado; $\mathbf{f}$ aspecto do novo direito que será subsumido no direito futuro. (a continuidade do direito se expressa na sequência c-f-i, e o progresso, em $\mathrm{A}<\mathrm{E}<\mathrm{C}^{15}$ ). C. Direito futuro.

Na realidade, a passagem do direito antigo $(A)$ para o novo direito (B) já futuro (C) não é um mero processo mecânico, senão de uma total reconstrução do sentido do direito. O direito romano (A) foi com relação ao direito germânico-latino medieval (B) não somente a per-

15 Com o signo " $<$ " queremos indicar que A é subsumido (em parte negado e em parte integrado) em $B$, significando este último um momento mais desenvolvido da consciência dos direitos humanos. Do direito romano ao medieval ou o moderno europeu há um processo de desenvolvimento. Na atualidade, há um salto na criatividade do direito, como a de uma época auroral que prenuncia a origem de uma nova época do direito pósburguês, direitos alternativos. Além disto, todo o problema dos direitos amadurecidos em toda cultura, a nahuatl, a maia ou a inca, a bantu, seja a da Índia ou a da China, o direito muçulmano, etc., nos fala do mesmo problema. No diálogo entre direitos haverá continuidades, haverá diferenças, haverá criatividade e também haverá aspectos que serão derrogados definitivamente como pertencentes ao passado; porém, o diálogo entre diversos direitos, de igual maneira, negará a total incomensurabilidade ou a superioridade universal de um direito (por exemplo, o ocidental moderno) sobre os outros (os do mundo pós-colonial), para ter o projeto futuro e mais rico de um direito dos povos que, fortalecendo os Estados, possa regular internacionalmente as estratégias destrutivas das corporações transnacionais, com suas burocracias tecnocráticas privadas e economicistas, que estão colocando a humanidade no início de uma final destruição. 
manência de alguns elementos (de $\boldsymbol{c}$ a $\boldsymbol{f}$ ), mas também a concepção totalmente nova de todos os direitos, porque o mundo da vida romana era realmente distinto do mundo cristão, tanto pelo sujeito de direito, por sua origem, por seu sentido, pelo significado da propriedade, da falta contra o direito, do castigo, etc. O mesmo acontecerá com relação ao direito burguês (C) ou a sua futura superação (que estaria antecipado pela "terceira" geração de direitos, não mais políticos nem sociais, e sim ecológicos, feministas, etc.)

Tudo isto nos indica, ademais, que, no corpo do direito e das instituições do Estado, deveria haver como um momento "crítico" por excelência que deixaria a porta aberta aos "novos direitos" que não teriam de ser impulsionados somente por lutas cruentas, difíceis, violentas dos novos atores sociais sem-direitos. Deveria haver na Constituição um artigo que indicasse a necessidade de poder incluir novos direitos não explicitados na Constituição (isto é, direitos assim não-constitucionais) e institucionalizar um Tribunal que não somente julgasse a constitucionalidade de uma lei ou ação, mas também a necessidade de uma reforma da Constituição para a inclusão de novos direitos. Seria um Tribunal supra-constitucional que permitiria à mesma Constituição produzir sua própria auto-reconstrução crítica no tempo. A Libertação dos sem-direitos poderia recorrer a este momento crítico do sistema do direito, onde se garantisse a legitimidade das lutas pelo reconhecimento de novos direitos não promulgados ao lado dos Direitos Humanos fundamentais da Constituição, nem regulados por lei alguma, necessariamente inexistente, por tratar-se de novos direitos dos quais não se teria tido conhecimento no passado.

Eis todo um capítulo da filosofia do direito que a Ética e a Política da Libertação têm por responsabilidade desenvolver teoricamente, para que o cidadão, o governante, as instituições e, em especial, o sistema do direito e seus órgãos de adjudicação possam ter sempre uma honesta e séria "pretensão política de justiça" em todas suas ações, normas, subsistemas, instituições ou na ordem política em geral, do âmbito nacional até o internacional . Desta maneira, a normatividade da luta pelo reconhecimento como libertação teria legitimidade antecipada, e o processo de deslegitimação do que deve derrogar perde sua 
angustiosa aparência e se torna um momento já antecipado também na necessária impossibilidade de uma legalidade perfeita ou legitimidade perfeita, impossibilidade exigida pela condição humana.

\section{REFERÊNCIAS}

DUSSEL, Enrique Domingo. Ética da libertação na idade da globalização e da exclusão. Tradução de Ephraim F. Alves, Jaime A. Clasen e Lúcia M. E. Orth. 2 ed. Petrópolis: Vozes, 2002.

. Hacia una filosofía política crítica. 2 ed. Bilbao: Desclée de Brouwer, 2011, p. 145-157.

Artigo enviado e aceito em abril de 2015. 